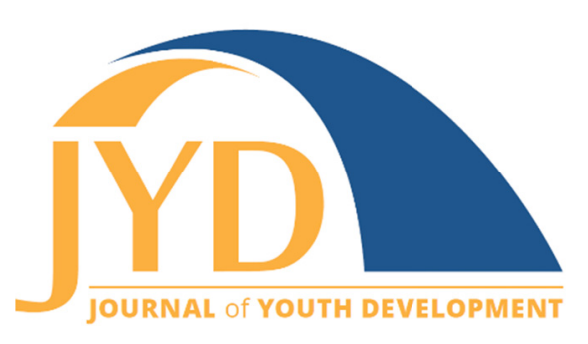

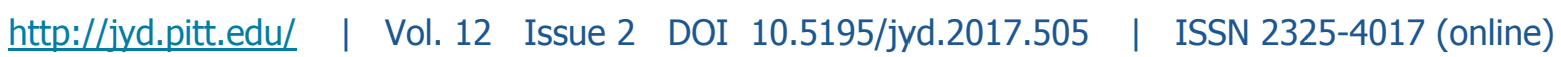

\title{
Seeing the Growth: Strengthening Teacher Connectedness Through Outward Bound Excursions
}

\author{
Shani Rose Turke \\ Johns Hopkins Bloomberg School of Public Health \\ sturke1@jhu.edu \\ Stephanie V. Caldas \\ University of North Texas \\ stephaniecaldas@my.unt.edu \\ Anna Kågesten \\ Johns Hopkins Bloomberg School of Public Health \\ anna.kagesten@gmail.com
}

Jennifer Parsons

Johns Hopkins Bloomberg School of Public Health

jparsons1128@yahoo.com

Ji Young Ahn

Johns Hopkins University

jahn27@jhu.edu

Peter Winch

Johns Hopkins Bloomberg School of Public Health

pwinch@jhu.edu

\section{Abstract}

Positive teacher-student relationships are protective for various health outcomes in adolescence. Evidence suggests that outdoor education programs, such as Outward Bound (OB), have the potential to encourage social skill development, but little research has investigated programs' effects on teacherstudent relationships. This study assessed high-school teacher connectedness following participation in $O B$ excursions. Twelve in-depth interviews with teachers and two focus groups with $O B$ instructors were conducted in the Chesapeake Bay area. Data were analyzed in Atlas.ti using an iterative, Grounded Theory methodology. As OB trips altered the role teachers often played in their classrooms, informants perceived increased trust with participating students as they developed shared memories. The effects of $O B$ extend beyond individual-level outcomes to encourage positive relationships between high-school teachers and their students. Given these findings, educators may want to consider incorporating outdoor

(cc) EY New articles in this journal are licensed under a Creative Commons Attribution 4.0 License. This journal is published by the University Library System, University of Pittsburgh and is cosponsored by the University of Pittsburgh Press. The Journal of Youth Development is the official peer-reviewed publication of the National Association of Extension 4-H Agents and the National AfterSchool Association. 
Outward Bound, Strengthening Teacher Connectedness

education programs into their curricula as a way to engage teachers and students beyond their prescribed roles in the classroom.

Key words: student-teacher relationship, growth and development, child and adolescent health, program evaluation, school psychology

\section{Introduction}

\section{Teacher Connectedness and its Impact on Student's Interpersonal Growth}

Social relationships are important for adjustment and functioning throughout life (Cassidy \& Shaver, 1999). During the developmental period of adolescence (ages 10 to 19), social relationships serve as protective factors and play an important role in developing resilience (Miller, Brehm, \& Whitehouse, 1998; Murray \& Greenberg, 2001; Werner, 1989). Positive and supportive relationships between teachers and students, often referred to as 'teacher connectedness,' have been found to be protective for a range of health outcomes in adolescence (Murray \& Malmgren, 2005). Teacher connectedness is characterized by open communication between teachers and students, as well as warmth, responsiveness and teachers' commitments to students' academic success and emotional health (Jennings \& Greenberg, 2009; Resnick et al., 1997; Thompson, Iachan, Overpeck, Ross, \& Gross, 2006).

Teacher connectedness is associated with motivation, behavioral and emotional engagement in school (Murray \& Greenberg, 2001; Skinner \& Belmont, 1993), and academic achievement (Hughes, Luo, Kwok, \& Loyd, 2008; Jennings \& Greenberg, 2009). High-school students who are connected to their teachers are more likely to engage in fewer risk behaviors and report better overall health and emotional wellbeing (McNeely \& Falci, 2004; Resnick et al., 1997; Thompson et al., 2006; Voisin et al., 2005). In a longitudinal study with at-risk children in Texas, Hughes et al. (2008) demonstrated that positive teacher-student relationships predicted increased engagement in school and higher academic achievement in math and science up to three years after baseline among a sample of 800 middle school students. A study of 550 incarcerated adolescents (aged 14-18) in Georgia found that after adjusting for socioeconomic and demographic variables, those reporting limited connection with teachers were nearly twice as likely to have used marijuana and amphetamines in the two months prior to detainment, when compared to peers reporting higher teacher connectedness (Voisin et al., 2005). McNeely and Falci (2004) used data from the National Longitudinal Study on Adolescent Health (Add Health) to assess the relationship between school connectedness, which includes components of teacher connectedness, and health-related outcomes in high school students, grades 7-12. 


\section{Outward Bound, Strengthening Teacher Connectedness}

Teacher support, defined as an adolescent feeling that the teacher is fair and cares about him/her, was statistically associated with a decreased likelihood of engaging in high-risk behaviors such as binge drinking, drug use, early sexual intercourse, and involvement in weapon-related violence (McNeely \& Falci, 2004).

\section{The Role of Outdoor Education Programming}

Outdoor education programs that target social and emotional learning, such as Outward Bound $(\mathrm{OB})$, may play a role in enhancing students' feelings of teacher connectedness and contribute to adolescent health and wellbeing (Durlak, Weissberg, \& Pachan, 2010; Hattie, Marsh, Neill, \& Richards, 1997). The OB program in the Chesapeake Bay area is an example of an outdoor education model that encourages interpersonal development between urban middle and highschool students and their teachers. OB offers outdoor wilderness courses ranging from single-day programs to several week excursions, during which students and teacher chaperones practice outdoor survival skills to facilitate team building and improve problem-solving skills (Baltimore Chesapeake Bay Outward Bound School, 2014).

Students who participate in outdoor education programs experience increased identity development (Duerden, Taniguchi, \& Widmer, 2012; Duerden, Widmer, Taniguchi, \& McCoy, 2009). A meta-analysis of 96 outdoor education programs found positive outcomes related to self-concept, locus of control, and leadership (Hattie et al., 1997). Previous research found increased identity development as well as growth in interpersonal skills and positive self-schema among students who participate in outdoor adventure programs (Russell, 2003; Sibthorp \& Morgan, 2011; Sibthorp, Paisley, Gookin, \& Furman, 2008). OB specifically has been found to contribute significantly to building skills needed for successful relationship development, such as emotional self-efficacy, (Sheard \& Golby, 2006) as well as improved communication and reflective thinking (Fleming \& Eames, 2005).

Despite the increased knowledge base related to the impact of OB among its youth participants, much of the previously mentioned research relies on quantitative methodologies to explore

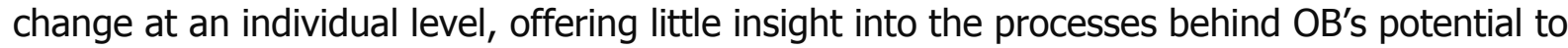
promote interpersonal growth or strengthen teacher connectedness. Given the limited research on either subject, we conducted an initial literature survey of outdoor education journals to better understand the ways in which OB's impact on youth participants had previously been researched (Table 1). In October 2015 we searched five prominent outdoor education and learning journals, using search terms related to interpersonal growth and teacher relationships 
Outward Bound, Strengthening Teacher Connectedness

within MeSH terms (Medical Subject Headings, the National Library of Medicine's tool for indexing articles for PubMed) in the fields of education and school-based psychology. The search was completed without any date restrictions.

Table 1. Initial Literature Survey Assessing Current Peer-Reviewd Literature Related to Interpersonal Growth among Teachers and Students through Outdoor Education Programming.

\begin{tabular}{|c|c|c|c|c|}
\hline Journal Title & $\begin{array}{l}\text { Total } \\
\text { number } \\
\text { of } \\
\text { Articles }^{a}\end{array}$ & $\begin{array}{l}\text { Number of } \\
\text { Relevant } \\
\text { Articles }^{b}\end{array}$ & $\begin{array}{l}\text { Number of } \\
\text { Relevant } \\
\text { Qualitative } \\
\text { Articles }\end{array}$ & $\begin{array}{l}\text { Number of } \\
\text { Relevant } \\
\text { Quantitative } \\
\text { Articles }\end{array}$ \\
\hline $\begin{array}{l}\text { Journal of Experiential } \\
\text { Education }\end{array}$ & 33 & 7 & 7 & 0 \\
\hline $\begin{array}{l}\text { Journal of Adventure Education } \\
\text { \& Outdoor Learning }\end{array}$ & 12 & 2 & 1 & 1 \\
\hline $\begin{array}{l}\text { Australian Journal of Outdoor } \\
\text { Education }\end{array}$ & 1 & 0 & 0 & 0 \\
\hline $\begin{array}{l}\text { Journal of Outdoor Recreation, } \\
\text { Education, and Leadership }\end{array}$ & 3 & 0 & 0 & 0 \\
\hline $\begin{array}{l}\text { Children, Youth, \& } \\
\text { Environments }\end{array}$ & 2 & 1 & 1 & 0 \\
\hline \multicolumn{5}{|c|}{$\begin{array}{l}\text { "Determined by whether the article contains key search terms of OB values such as "group dynamics," "teacher," } \\
\text { and "relationship" } \\
\text { "Determined by whether the article suggests changes in teacher-student relationships and translation of OB skills to } \\
\text { the classroom }\end{array}$} \\
\hline
\end{tabular}

In four of the five journals (Journal of Experiential Education, Journal of Adventure Education \& Outdoor Learning, Australian Journal of Outdoor Education, and the Journal of Outdoor Recreation, Education, and Leadership), we first searched for articles related to interpersonal relationships. We then separately searched for articles mentioning "teachers" and "relationships." After searching for these distinct groups, we reviewed abstracts that discussed both search terms. Since the Journal of Adventure Education \& Outdoor Learning does not focus exclusively on outdoor education or experiential learning, we first narrowed our search 


\section{Outward Bound, Strengthening Teacher Connectedness}

results for this journal to the pool of articles explicitly referring to outdoor education, finding a total of 369 articles.

Across all five journals, the use of these two search terms identified a total of 51 articles (Table 1). From the remaining pool, we reviewed the abstracts to further narrow our scope, focusing on studies looking at interpersonal relationships between teachers and students in the context of outdoor education using qualitative methodologies.

All studies reviewed $(n=51)$ focused on describing the mechanisms of change on individual behavior and growth, particularly related to middle and high school youth participating in outdoor education programs. Some also discussed the effects of outdoor education programming on students' relationships with their peers, but few described programs' effects on teachers or teacher connectedness $(n=10)$. One paper found through our search (Rowley, 1987) urged researchers in outdoor education to adopt qualitative methodologies, arguing that important insights could be gained from this approach. In our review, however, only nine articles explored teacher-student relationships from a qualitative perspective.

One mixed-methods study used qualitative data from camp journals to supplement questionnaire data with 93 secondary students in Singapore (Ee \& Ong, 2014). Students who participated in the 2-day camp showed positive outcomes in self-awareness, social awareness, self-management and relationship management, including relationships with teachers, though their data did not include additional details on teacher connectedness. Another study investigated the impact of an outdoor Environmental Services Program in Ontario, Canada through interviews with teachers and students in grades 10 and 11 , and found that the program improved open dialogue between teachers and students and resulted in "pedagogical kinships" among teachers, but did not go further in exploring teacher-student relationships (Breunig, Murtell, Russell, 2015). A study likely most relevant to the current research investigated an integrated outdoor education and classroom program, through focus group interviews with parents, teachers, and 671 students across nine schools (Dismore \& Bailer, 2005). Results suggested that students who participated in the outdoor education program were more motivated and engaged in learning, and that teachers were more likely to view their classroom in a positive light and to share successes with their students (Dismore \& Bailer, 2005). Similar to the other studies, however, the authors did not further investigate teacher connectedness and the program's impact on teacher-student relationships. These findings highlight the need for the current study, which seeks to better understand how programs like OB impact teacher- 


\section{Outward Bound, Strengthening Teacher Connectedness}

student relationships, and the mechanisms through which change occurs at an interpersonal level.

\section{Current Study}

The current study explored how OB participation affects both teachers and adolescent students, specifically aiming to:

1. Understand teacher-student relationships and interactions before, during and after engagement in OB activities in the Chesapeake Bay area, and

2. Explore how such experiences might shape teacher connectedness.

\section{Methods}

\section{Participants}

The current study made up the qualitative portion of a larger mixed-methods evaluation of the OB Chesapeake Bay program conducted by the Johns Hopkins Bloomberg School of Public Health, with support from the Department of Justice, Office of Juvenile Justice and Delinquency Prevention, and the Johns Hopkins Urban Health Institute. ${ }^{1,2}$

We conducted 12 in-depth interviews (IDI) with five female teachers, three male teachers and one OB female staff member, for a total of 9 participants, most between 25-35 years old. The same interviewer met twice with three informants; others were interviewed once. Teachers came from three small to mid-sized public charter and private high schools (grades 9-12) serving urban or suburban communities in the Chesapeake Bay area. The socioeconomic status of households served by these schools varied widely depending on school location and model (e.g. private boarding school compared to a public charter school).

${ }^{1}$ Human Subjects Approval: The Institutional Review Board at Johns Hopkins Bloomberg School of Public Health approved this study as well as all study materials before data collection began.

${ }^{2}$ Acknowledgements: The research team thanks Dr. Pam Surkan, Dr. Steve Harvey, and Emily Hurley, MPH, for their guidance during data collection and in reviewing preliminary drafts of the manuscript. The team also acknowledges the public and private schools that agreed to participate. 
We also conducted two focus group discussions (FGD) with ten female and six male $\mathrm{OB}$ instructors, ages 25-30 years for a total of 16 participants. All OB instructors had worked with the Chesapeake OB regional chapter for between one and seven years. Between IDIs and FGDs, we directly engaged a total of 25 participants.

\section{Procedure}

Our sampling approach was iterative, relying on initial findings to shape further data collection activities (Charmaz, 2006; Strauss \& Corbin, 1994). Aiming for maximum variation, we reached out to teachers from urban and suburban schools, as well as OB program staff in the Chesapeake Bay area, sampling both by demographics of the school communities (geographic location and income level) and by type of respondent (Patton, 2005).

We conducted all IDIs and FGDs between February and April 2014. We interviewed teachers in quiet, confidential locations at high schools where they worked and conducted FGDs with instructors on $\mathrm{OB}$ facility grounds. All interviews began by obtaining oral consent. IDIs lasted between 30 and 60 minutes, FGDs between 25 and 35 minutes. We also included the transcription of a reflective speech about $\mathrm{OB}$ written by a teacher informant.

\section{Instrumentation}

We used an unstructured guide for IDIs and a semi-structured guide for FGDs, generating multiple iterations of the IDI guide as previous rounds of data collection informed question development for successive interviews. Initial IDIs with teachers explored perceptions of OB's impact on student and school environment outcomes. We conducted follow-up interviews with teachers when we felt relevant topics merited further exploration, particularly around emerging themes such as changes in teacher-student relationships and translation of OB skills to the classroom. FGDs with instructors assessed the perceived values of $\mathrm{OB}$, teacher roles, group dynamics, and teamwork. We used reflective probes throughout data collection to encourage depth and narrative from informants. Interviews were audio recorded and transcribed verbatim, adding handwritten notes of non-verbal cues. 


\section{Data Analysis}

Consistent with Grounded Theory (Charmaz, 2006; Strauss \& Corbin, 1994), we engaged in an iterative process to form analytical links between emerging themes in the development of a framework grounded in the data. Each researcher individually coded the first three pages of one transcript line-by-line, from which we developed an initial codebook used for subsequent focused coding. When appropriate, we retained in-vivo codes to preserve participants' language (Charmaz, 2006). We used successive rounds of memoing, in addition to regular meetings to compare emerging themes (Miles \& Huberman, 1994). We retained 68 codes in the finalized master codebook used for the remaining transcripts, and identified 14 codes informative to our understanding of teacher connectedness. All coding and analysis were conducted using Atlas.ti (v7) ("ATLAS.ti: Qualitative Data Analysis," 2013).

We relied on a number of strategies to enhance credibility of findings. With the master code list, we re-coded earlier transcripts to ensure that coding was consistent across all interviews and focus groups. Three members of the research team went through each of these codes independently to triangulate themes present across different types of informants and schools, as well as socioeconomic community profiles. This allowed us to draw connections and connect relevant themes to shape theory development.

\section{Results}

Our initial research questions sought to evaluate the impact of $O B$ within the context of the existing literature, theorizing that $\mathrm{OB}$ experiences would clearly connect to overt student, teacher, and school-environment outcomes. Instead, through iterative coding (Charmaz, 2006), we identified a pathway through which OB experiences strengthened and enhanced teacher connectedness. Figure 1 introduces a framework for this pathway, highlighting key themes of student and teacher familiarity before $\mathrm{OB}$, mechanisms of relationship modification and enhancement during the trip, and teachers' perceptions of relationships after the excursion.

\section{Teacher connectedness before OB}

There was substantial variation in how informants described the nature of teacher-student relationships prior to OB. Some teachers drew on pre-existing relationships with students by recruiting youth to OB they already knew well from their role as advisors or teachers. Other 
Outward Bound, Strengthening Teacher Connectedness

teachers did not rely on pre-existing relationships in recruiting students for $\mathrm{OB}$; one example being a private boarding school where OB excursions were part of orientation activities for incoming freshmen. Regardless of how teachers described their existing relationship with students, most emphasized the importance of building close relationships and that extracurricular activities such as $\mathrm{OB}$ are part of this philosophy. One teacher even saw $\mathrm{OB}$ as an extension of his school's overarching mission to holistically nurture students through mentorship:

One of the phrases we use is, 'cura personalis,' which is Latin for 'care of the whole person,' and I think that the whole idea is that we are not just academic educators, but that we are mentoring the student growing up, so certainly this trip is a great example of how to do that in another venue. (Male teacher, urban private school)

Figure 1. A Framework of the Process through Which Chesapeake Bay OB Programming May Strengthen and Enhance Teacher-Student Connectedness.

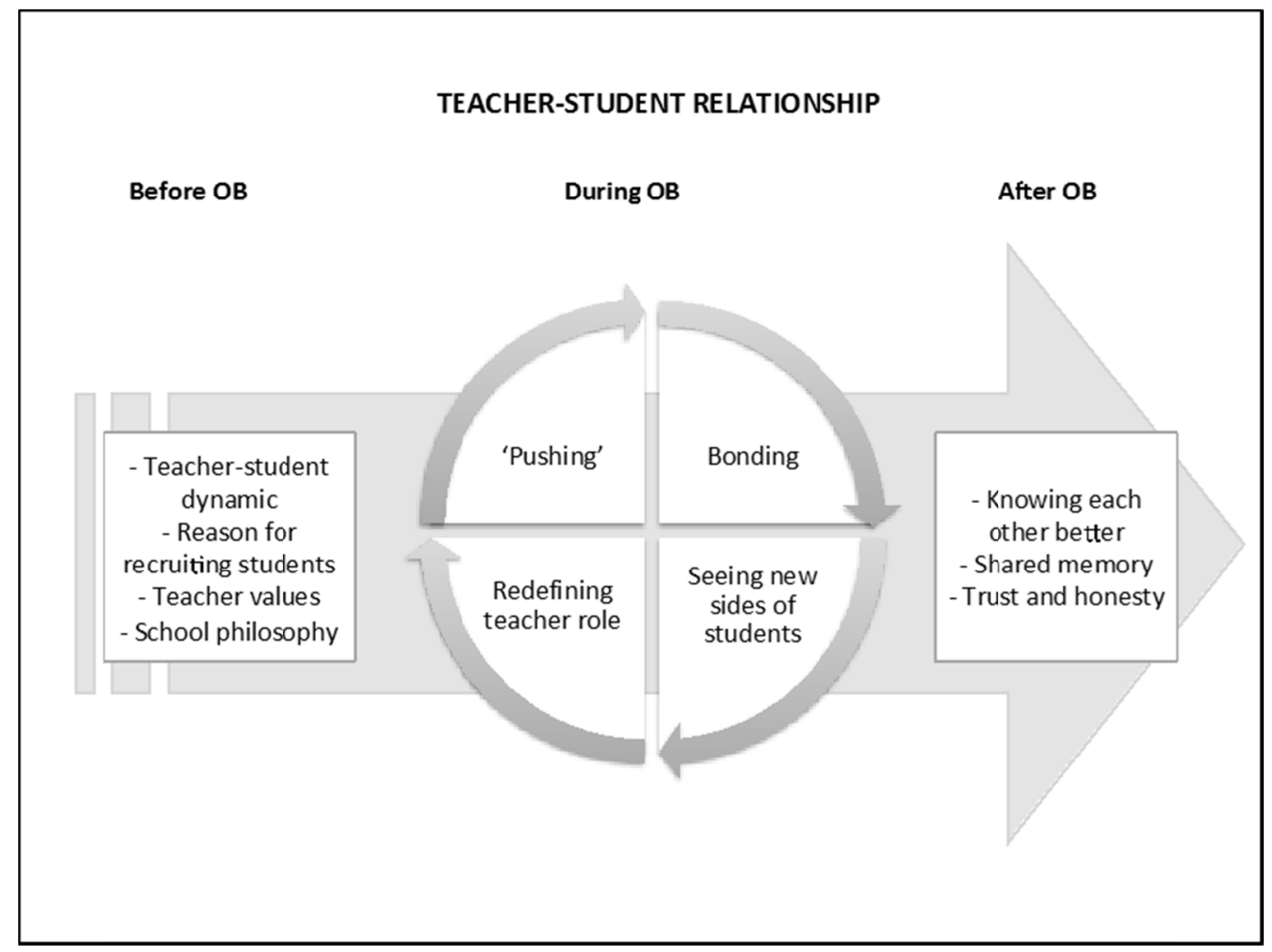


Outward Bound, Strengthening Teacher Connectedness

\section{Teacher-student relationships during OB}

Through coding, we identified four key mechanisms described by participants: pushing through adversity, bonding through this process, seeing new sides of participants, and navigating teacher roles. Teachers and instructors alike discussed $\mathrm{OB}$ as a means of getting out of your comfort zone in order to cultivate personal growth. Specifically, informants mentioned the importance of pushing students beyond their point of comfort, yet not to the point of crisis, sometimes referred to as panic zones. Pushing could occur in a variety of situations depending on what individuals perceived to be difficult. Many teachers noted how being in the wilderness was a main source of difficulty for themselves as well as students-many of whom had 'never left the city, ever in their lives" (Female teacher, urban public charter school). Others were mainly challenged by continuously sharing space and lacking privacy.

Informants often related the process of pushing to interpersonal relationship development. Teachers reflected on how their own presence as a familiar adult helped students to step out of their comfort zones. As one teacher remarked:

There are times where students are being pushed, they're physically or mentally exhausted, they may not be in a good space, they may not wanna be there anymore. And, so they kind of have to have that outside person to either let them vent, consult them if they're having issues, feel like they're not trapped in this situation. And also be there to kind of push them... or to keep them going when the days are really long or when you really wanna take a shower... I think it's really important and a lot of the students when they came back they told me that it helped, that I was like their little morale push to get through it. (Female teacher, urban public charter school)

There were also situations that pushed teachers themselves. Many saw these as opportunities to bond with students as they faced similar feelings of discomfort and fear. One teacher described how his own 'breakdown' allowed him to better support a student:

We just kind of talked through how she was feeling, and how, my first year on the trip, I had a breakdown one night after the rain, just 'cause it's the first time I'd been away from my wife and kids for that long, you know, same thing for her - first time she'd been away from her family and she came to boarding school and 
Outward Bound, Strengthening Teacher Connectedness

immediately goes out into the woods and all that kinda all compiled together. (Male teacher, urban private school)

Informants highlighted that the $\mathrm{OB}$ trip was the first time that some students saw their teachers outside of their authority roles, and that in many cases this was a key process for building more profound relationships. One teacher described this happening as a result of being "out of the academic environment," saying:

So you could have people... more open to talk about life (...)

versus 'why didn't you do your homework?' or 'what's going on, you're kind of failing my class' and things like that... It just kind of all got deeper and they saw me in a different light, because... when you're the teacher in the classroom, and (...) if they see you outside of the school, it's weird for them... they don't think you have a normal life." (Female teacher, urban public charter school)

Another teacher corroborated this in discussing the value of having students see her vulnerability:

I'm afraid of heights and they want us to like climb this thing, but I think that's good for them to see, you know just because I'm competent in one sphere doesn't mean I don't turn around [and] have to learn and perhaps be nervous and embarrassed...in a different setting. (Female teacher, urban private school)

Teachers also remarked on the transformative power of seeing new sides of their students, as they challenged and overcame obstacles. Notably, this modified the way that some viewed students. As described by one informant:

I think $[O B]$ is a great learning experience for teenagers... they sort of want to mutiny against each other, like 'I can't deal with you anymore' and its like 'well guys, you have to...we've still got another 20 miles to go on this trail.'...Seeing the growth at that age ...is really powerful. (Male teacher, urban private school) Informants described a shift in power dynamics and the role of the teacher. Several teachers reported struggling with relinquishing their authority position, and not being sufficiently knowledgeable in contrast to the instructor. Teachers also highlighted that they were often times told by instructors to step back and to allow their students to achieve greater autonomy. As one instructor said, this often made teachers' uncomfortable: 
Outward Bound, Strengthening Teacher Connectedness

Sometimes teachers are not comfortable relinquishing control to their students, or watching students struggle, and that struggle process is what ultimately pushes them to be able to step up to stretch their comfort zone, if you're always comfortable, you're not learning. So, [teachers] sometimes have trouble watching kids go through that process. (Male $O B$ instructor)

\section{Teacher-student relationships after $O B$}

We noted differences in the way teachers characterized their relationships with participating students before and after OB excursions. Teachers discussed how they got to know their students better through $\mathrm{OB}$, creating a mutual compassionate understanding that extended beyond the trip. Oftentimes this was characterized by increased openness and honesty. One teacher talked about how knowing students better from $\mathrm{OB}$ increased his connection to them after the trip:

I do feel like you see such a different side of kids out there... I'll have kids that I'll spend 5 days on that trip together with them, and I won't ever teach them, I won't ever coach them, I'll never have any other interaction with them, and still, their senior year, 3 years later, I still feel closer to them than I do with most the other students that I know. (Male teacher, private boarding school)

Several teachers described relying on shared memory with students who had participated in the same OB trip. Teachers mentioned being able to motivate students more effectively by drawing on common challenges faced. When asked about the impact of OB on students, one informant highlighted this as a value of the trip:

Do we all have that shared memory? Yes. Do I bring it up to one of them occasionally, you know, as sort of, in a light moment or you know, a moment where they need like a push, like a 'hey, let's keep going here?' Yes, I do. (Male teacher, urban private school)

Finally, some teachers stated that the $\mathrm{OB}$ excursion did not fundamentally change classroom dynamics, but rather taught them more effective pedagogic techniques for connecting with students. For other teachers, changing interactions with students was mainly a result of their own personal learning. As one informant remarked: 
Outward Bound, Strengthening Teacher Connectedness

I tried to really play up this idea of... students helping other students like, "Hey I've gotten this far but I need help from you," like always look to another student first or...if a student finishes first, you can offer help. That was my small way of finding a classroom application of being dependent upon peers. (Female teacher, urban private school)

\section{Discussion}

The current research sought to understand how OB programming in the Chesapeake Bay area shaped the relationships of participating teachers and students, providing valuable depth of information to the body of outdoor education research that has often relied on quantitative methodologies to explore individual-level outcomes. Findings from our initial literature survey revealed an abundance of information on the impact of outdoor education on the development of social skills, such as leadership, self-efficacy, and communication skills. However, the literature survey also revealed a critical lack of qualitative research investigating the underlying mechanisms governing OB's effects on teacher-student relationships, further justifying the current qualitative approach.

Utilizing Grounded Theory (Charmaz, 2006; Strauss \& Corbin, 1994), we developed a framework for understanding how $\mathrm{OB}$ participation molds teacher connectedness. Prior to $\mathrm{OB}$ trips, teachers had varying levels of familiarity with the students they chaperoned. Through core experiences of the OB program, relationships between teachers and students were reshaped through processes of pushing, bonding, seeing new sides of students, and redefining teacher roles. After OB trips, teachers described knowing their students better, drawing on shared memory to relate to student participants, and a sense of greater openness and trust in their relationships with students.

Research to date has largely focused on individual-level outcomes of OB excursions. In 1976, Walsh \& Golins constructed a framework for the ways in which $O B$ affects individual qualities such as openness, esteem, and acceptance of others, emphasizing the role of instructors in building participants' skills. The inclusion of teachers in this study allowed us to move beyond participant-instructor interactions, discover qualities unique to school OB programs, and develop a model for understanding how OB school programs may impact teacher connectedness. A 
Outward Bound, Strengthening Teacher Connectedness

central theme was that of a shared memory between teachers and students following $\mathrm{OB}$, similar to what Walsh \& Golins (1976) refer to as shared language between participants:

It is like becoming a speaker of a language one shares with somebody. The language of that interaction becomes a part of oneself, and the standards of the style and clarity that one adopts for that interaction becomes a part of one's own standards (Walsh \& Golins, 1976, p. 12).

It becomes evident that the shared memory of an $\mathrm{OB}$ trip between teachers and students serves as a reminder of challenges mastered together, increasing mutual trust and respect.

The process of pushing through challenges emerged as a key element to building positive interpersonal connections. This approach reflects that of experiential education, where teachers encourage students to rely on their own capacities in surmounting challenges (Kraft \& Sakofs, 1985). Our results show that teachers themselves were 'active learners' during OB experiences, which according to experiential education philosophy engender respect for student competencies and encourage reflection about teaching styles (Kraft \& Sakofs, 1985).

Another important finding is that of teachers' redefining their roles with students. It became clear that teachers' overall value about what their relationship to students should beexemplified by statements such as caring for the whole person-largely shaped the extent of mentorship with students during and after the trip. For some, OB helped strengthen existing bonds. Other teachers became mentors during $\mathrm{OB}$, moving beyond the role of academic authorities. Interestingly, OB is not inherently a mentoring intervention. Yet, our findings show that the program may help foster many components of true mentoring programs (Rhodes, Grossman, \& Resch, 2000), including the formation of supportive alliances between adults and adolescents (Grossman \& Tierney, 1998; Rhodes et al., 2000). Such relationships with teachers can increase students' motivation to engage both in and outside an academic environment (Herrera, Grossman, Kauh, \& McMaken, 2011).

However, the longevity of connectedness between teachers and students following OB depends heavily on the school environment. Our findings concur with Walsh and Golins (1976) in that "no educative experience can stand by itself, no matter how worthwhile; and that there must be a continuum of such experiences throughout a person's life" (p. 15).

Although the results from our study indicate that teachers felt increasingly connected to students following an excursion, $\mathrm{OB}$ school programs are merely one way of building positive 


\section{Outward Bound, Strengthening Teacher Connectedness}

teacher-student relationships. Future research is needed to better understand the long-term effects OB may have on teacher connectedness.

\section{Limitations}

A significant limitation to the current scope of this research is the lack of student perspectives in how OB programs shape teacher connectedness. Gaining students' point of view would have allowed us to triangulate salient themes presented by teachers and offer alternate perspectives on how $\mathrm{OB}$ impacts teacher-student relationships. Research has suggested that the quality of these relationships matters, and negative teacher-student interactions can exacerbate or worsen developmental outcomes (Hughes, Cavell, \& Wilson, 2001). Our study did not uncover any discussion around such negative teacher-student relationships or how OB may impact such relationships negatively if the program is not conducted well. This may reflect a limitation of our study design in that we spoke only with adults (either teachers or OB instructors) who had a vested interest in seeing the program succeed in their school setting.

Moreover, our sample of teachers was restricted to those teaching in urban and suburban areas, as well as in private and public charter schools, meaning we cannot assume these informants' experiences are reflective of all teachers participating in OB. While the framework developed may not be generalizable, we posit that it remains transferable to other intervention contexts, and serves a valuable contribution to the literature as one of the first theoretical models for understanding how an outdoor education program may modify and impact teacher connectedness.

In terms of reflexivity (Patton, 2005), we acknowledge our own educational backgrounds and previous positive experiences with outdoor education influenced data collection and analysis. In addition, time spent with OB staff and instructors may have focused our coding process on certain themes, despite the intended inductive approach. Despite these limitations, our analytical approach, moving from response to topical coding strengthens this research's credibility.

\section{Conclusion}

Our findings elucidate a process by which $\mathrm{OB}$ helps establish and strengthen teacher connectedness, improving mutual understanding, developing a shared memory, and cultivating 
Outward Bound, Strengthening Teacher Connectedness

greater openness between teachers and students. Given the role teacher connectedness plays in promoting the wellbeing of young people, creating opportunities to foster such relationships is critical. In future research, examining these relationships from the perspective of the student would provide further insight into how OB programs influence teacher-student connectedness. Nonetheless, this research offers a novel mechanism by which to understand how OB programs and similar outdoor education programs may promote teacher connectedness and develop interpersonal skills among both adult and adolescent participants.

\section{Implications for Educators}

This research provides evidence to suggest that schools seeking to develop and grow the relationships of teachers and students beyond the classroom should consider incorporating outdoor education programs into their curriculum. While OB alone may not lead to overt changes, our findings do suggest that outdoor education programs, as part of a sustained engagement on the part of school systems, can contribute to inter-personal growth between educators and their students.

Moreover, teachers who participated in OB reported experiencing an increase in their ability to be responsive to students. Socially and emotionally competent teachers demonstrate more effective classroom management, associated with positive social, emotional, and academic student outcomes (Howes, 2000; Skaalvik \& Skaalvik, 2010; Wentzel, 2002). In addition, teachers with the resources to effectively manage their classrooms and school environments are more proactive (Hamre \& Pianta, 2005) and less likely to experience burnout (Marzano \& Pickering, 2003). Given research indicating the importance of teacher social and emotional competence in developing relationships with students (Jennings \& Greenberg, 2009), OB may help teachers strengthen bonds with students beyond only those who go on OB excursions.

The framework developed through this research suggests students and teachers will benefit from schools that are supportive of developing reoccurring environments where educators and students are required to engage one another outside the roles prescribed to them within an academic context. Teachers from one school in this study noted that all incoming students in their school participate in an $\mathrm{OB}$ excursion as an introduction experience to their peers and educators. Repeated engagements at the school-level may be an effective strategy for other schools as well. School-based mentoring programs designed to help foster teacher connectedness may have similar effects as those discussed in this research and should be explored by schools looking to foster better relationships between educators and their students 


\section{Outward Bound, Strengthening Teacher Connectedness}

(Grossman \& Tierney, 1998; Herrera et al., 2011; Karcher, 2008; Portwood, Ayers, Kinnison, Waris, \& Wise, 2005).

\section{References}

ATLAS.ti: Qualitative Data Analysis. (Version 7). (2013). Retrieved from http://www.atlasti.com/index.html

Baltimore Chesapeake Bay Outward Bound. (2014). Retrieved from http://outwardboundbaltimore.org

Breunig, M., Murtell, J., \& Russell, C. (2015). Students' experiences with/in integrated Environmental Studies Programs in Ontario. Journal of Adventure Education and Outdoor Learning, 15(4), 267283. doi:10.1080/14729679.2014.955354

Cassidy, J., \& Shaver, P. R. (1999). Handbook of attachment: Theory, research, and clinical applications (Vol. 236): Guilford Publications.

Charmaz, K. (2006). Constructing grounded theory: A practical guide through qualitative analysis. Pine Forge Press.

Dismore, H., \& Bailey, R. (2005). "If only": Outdoor and adventurous activities and generalised academic development. Journal of Adventure Education and Outdoor Learning, 5(1), 9-19. doi:10.1080/14729670585200561

Duerden, M. D., Taniguchi, S., \& Widmer, M. (2012). Antecedents of identity development in a structured recreation setting: A qualitative inquiry. Journal of Adolescent Research, 272), 183-202. doi: $10.1177 / 0743558411417869$

Duerden, M. D., Widmer, M. A., Taniguchi, S. T., \& McCoy, J. K. (2009). Adventures in identity development: The impact of adventure recreation on adolescent identity development. Identity, 9(4), 341-359. doi:10.1080/15283480903422806

Durlak, J. A., Weissberg, R. P., \& Pachan, M. (2010). A meta-analysis of after-school programs that seek to promote personal and social skills in children and adolescents. American Journal of Community Psychology, 45(3-4), 294-309. doi:10.1007/s10464-010-9300-6

Ee, J., \& Ong, C. W. (2014). Which social emotional competencies are enhanced at a social emotional learning camp? Journal of Adventure Education and Outdoor Learning, 14(1), 24-41. doi:10.1080/14729679.2012.761945

Fleming, J., \& Eames, C. (2005). Student learning in relation to the structure of the cooperative experience: Research report. Asia-Pacific Journal of Cooperative Education 6(2), 26-31.

Grossman, J. B., \& Tierney, J. P. (1998). Does mentoring work? An impact study of the Big Brothers Big Sisters program. Evaluation review, 22(3), 403-426. 
Outward Bound, Strengthening Teacher Connectedness

Hamre, B. K., \& Pianta, R. C. (2005). Can instructional and emotional support in the first-grade classroom make a difference for children at risk of school failure? Child Development, 76(5), 949-967. doi:10.1111/j.1467-8624.2005.00889.x

Hattie, J., Marsh, H. W., Neill, J. T., \& Richards, G. E. (1997). Adventure education and Outward Bound: Out-of-class experiences that make a lasting difference. Review of Educational Research, $6 \pi 1$ ), 43-87. Retrieved from http://rer.sagepub.com/content/67/1/43.abstract

Herrera, C., Grossman, J. B., Kauh, T. J., \& McMaken, J. (2011). Mentoring in schools: An impact study of Big Brothers Big Sisters school-based mentoring. Child Development, 82(1), 346-361. Retrieved from http://onlinelibrary.wiley.com/doi/10.1111/j.1467-8624.2010.01559.x/abstract

Howes, C. (2000). Social-emotional classroom climate in child care, child-teacher relationships and children's second grade peer relations. Social Development, $9(2), 191-204$. doi:10.1111/14679507.00119

Hughes, J. N., Cavell, T. A., \& Wilson, V. (2001). Further support for the developmental significance of the quality of the teacher-student relationship. Journal of School Psychology, 39(4), 289-301. doi: 10.1016/S0022-4405(01)00074-7

Hughes, J. N., Luo, W., Kwok, O. M., \& Loyd, L. K. (2008). Teacher-student support, effortful engagement, and achievement: A 3-year longitudinal study. Journal of Educational Psychology, 100(1), 1- 14. doi:10.1037/0022-0663.100.1.1

Jennings, P. A., \& Greenberg, M. T. (2009). The prosocial classroom: Teacher social and emotional competence in relation to student and classroom outcomes. Review of Educational Research, 79(1), 491-525.

Karcher, M. J. (2008). The study of mentoring in the learning environment (SMILE): a randomized evaluation of the effectiveness of school-based mentoring. Prevention Science, 9(2), 99- 113. doi:10.1007/s11121-008-0083-z

Kraft, R. J., \& Sakofs, M. (1985). The theory of experiential education. Dubuque, IA: Kendall/Hunt. Marzano, R., Marzano, J. S., \& Pickering, D. (2003). Classroom management that works: Research-based strategies for every teacher. Alexandria, VA: ASCD.

McNeely, C., \& Falci, C. (2004). School connectedness and the transition into and out of health-risk behavior among adolescents: A comparison of social belonging and teacher support. Journal of School Health, 74(7), 284-292. doi:10.1111/j.1746- 1561.2004.tb08285.x

Miles, M. B., \& Huberman, A. M. (1994). Qualitative data analysis: An expanded sourcebook. Thousand Oaks, CA: Sage.

Miller, G. E., Brehm, K., \& Whitehouse, S. (1998). Reconceptualizing school-based prevention for antisocial behavior within a resiliency framework. School Psychology Review, 27, 364-379. 


\section{Outward Bound, Strengthening Teacher Connectedness}

Murray, C., \& Greenberg, M. T. (2001). Relationships with teachers and bonds with school: Social emotional adjustment correlates for children with and without disabilities. Psychology in the Schools, 38(1), 25-41. doi:10.1002/1520-6807(200101)38:1<25::AID- PITS4>3.0.CO;2-C

Murray, C., \& Malmgren, K. (2005). Implementing a teacher-student relationship program in a highpoverty urban school: Effects on social, emotional, and academic adjustment and lessons learned. Journal of School Psychology, 43(2), 137-152. doi:http://dx.doi.org/10.1016/j.jsp.2005.01.003

Patton, M. Q. (2005). Qualitative Research. In B. S. Everitt \& D. Howell, Encyclopedia of Statistics in Behavioral Science (pp. 1633-1636). Hoboken, NJ: John Wiley \& Sons, Ltd.

Portwood, S. G., Ayers, P. M., Kinnison, K. E., Waris, R. G., \& Wise, D. L. (2005). YouthFriends: outcomes from a school-based mentoring program. Journal of Primary Prevention, 26(2), 129-188. doi:10.1007/s10935-005-1975-3

Resnick, M. D., Bearman, P. S., Blum, R. W., Bauman, K. E., Harris, K. M., Jones, J., ... Udry, J. R. (1997). Protecting adolescents from harm. Findings from the National Longitudinal Study on Adolescent Health. Jama, 278(10), 823-832. Retrieved from http://jama.jamanetwork.com/article.aspx?articleid=418137

Rhodes, J. E., Grossman, J. B., \& Resch, N. L. (2000). Agents of change: Pathways through which mentoring relationships influence adolescents' academic adjustment. Child Development, 71(6), 1662-1671. Retrieved from http://onlinelibrary.wiley.com/doi/10.1111/14678624.00256/abstract

Rowley, J. (1987). Adventure education and qualitative research. Journal of Experiential Education, 10(2), 8-12. doi:10.1177/105382598701000202

Russell, K. (2003). An Assessment of outcomes in outdoor behavioral healthcare treatment. Child and Youth Care Forum, 32(6), 355-381. doi:10.1023/B:CCAR.0000004507.12946.7e

Sheard, M., \& Golby, J. (2006). The efficacy of an outdoor adventure education curriculum on selected aspects of positive psychological development. Journal of Experiential Education, 29(2), 187-209. doi: $10.1177 / 105382590602900208$

Sibthorp, J., \& Morgan, C. (2011). Adventure-based programming: Exemplary youth development practice. New Directions for Youth Development, 2011(130), 105-119. doi:10.1002/yd.400

Sibthorp, J., Paisley, K., Gookin, J., \& Furman, N. (2008). The Pedagogic value of student autonomy in adventure education. Journal of Experiential Education, 31(2), 136-151. doi: $10.1177 / 105382590803100203$

Skaalvik, E. M., \& Skaalvik, S. (2010). Teacher self-efficacy and teacher burnout: A study of relations. Teaching and Teacher Education, 26(4), 1059-1069. doi:http://dx.doi.org/10.1016/j.tate.2009.11.001 
Outward Bound, Strengthening Teacher Connectedness

Skinner, E. A., \& Belmont, M. J. (1993). Motivation in the classroom: Reciprocal effects of teacher behavior and student engagement across the school year. Journal of Educational Psychology, 85(4), 571-581. doi:10.1037/0022-0663.85.4.571

Strauss, A., \& Corbin, J. (1994). Grounded theory methodology. Handbook of qualitative research, 273285.

Thompson, D. R., Iachan, R., Overpeck, M., Ross, J. G., \& Gross, L. A. (2006). School connectedness in the health behavior in school-aged children study: the role of student, school, and school neighborhood characteristics. Journal of School Health, 76(7), 379-386. doi:10.1111/j.17461561.2006.00129.x

Voisin, D. R., Salazar, L. F., Crosby, R., Diclemente, R. J., Yarber, W. L., \& Staples-Horne, M. (2005). Teacher connectedness and health-related outcomes among detained adolescents.J Adolesc Health, 37(4), 337. doi:10.1016/j.jadohealth.2004.11.137

Walsh, V., \& Golins, G. (1976). The Exploration of the Outward Bound Process. Denver: Colorado Outward Bound School.

Wentzel, K. R. (2002). Are effective teachers like good parents? Teaching styles and student adjustment in early adolescence. Child Development, 73(1), 287-301. doi:10.1111/1467-8624.00406

Werner, E. E. (1989). High-risk children in young adulthood: A longitudinal study from birth to 32 years. American Journal of Orthopsychiatry, 59(1), 72-81. doi:10.1111/j.1939-0025.1989.tb01636.x 